\title{
Actions of cholera toxin and the prevention and treatment of cholera
}

\author{
Jan Holmgren
}

Institute of Medical Microbiology, University of Göteborg, S-413 46 Göteborg, Sweden

The drastic intestinal secretion of fluid and electrolytes that is characteristic of cholera is the result of reasonably well understood cellular and biochemical actions of the toxin secreted by Vibrio cholerae. Based on this understanding it is possible to devise new techniques for the treatment and prophylaxis of cholera to complement those based on fluid replacement therapy and sanitation.

CHOLERA patients have characteristically watery diarrhoea which leads to dehydration and metabolic acidosis. If untreated, this fluid loss rapidly leads to death. The disease is caused by an intestinal infection with Vibrio cholerae. These bacteria adhere to and colonize the small intestine and secrete an exotoxincholera toxin-that binds to receptors on the mucosal cells and stimulates intestinal adenylate cyclase activity. The resulting increase in cyclic AMP then causes diarrhoea and fluid loss by inhibiting uptake of sodium chloride by the villi as well as by stimulating active chloride secretion by crypt cells ${ }^{1}$.

Koch, who identified $V$. cholerae as the causative agent of cholera, had in 1887 already proposed that the disease was toxin-mediated but it was not until 1959 that the Indian scientists $\mathrm{De}^{2}$ and Dutta ${ }^{3}$ convincingly demonstrated the existence of a cholera toxin. This was purified ${ }^{4.5}$, and its effect on the adenylate cyclase-cyclic AMP system soon established ${ }^{6-10}$. Since then, activation of adenylate cyclase by cholera toxin has been shown to occur in most mammalian cell types, the structure-function relationship of the toxin has been defined, the cell membrane receptor identified and, most recently, the mode of action of the toxin on adenylate cyclase explained in considerable detail.

This knowledge of the cholera toxin has made it a useful tool for cell biologists, biochemists and physiologists interested in aspects of cell membrane and cyclic nucleotide research that are essentially unrelated to cholera. It has also suggested various possibilities for novel approaches to prevention and treatment of disease. My main intention here is to describe the cellular action of cholera toxin and to discuss the possible exploitation of this knowledge in the design of vaccines, receptor-prophylactic agents, and antisecretory drugs against cholera.

\section{The cholera toxin molecule}

Cholera toxin is a protein with two types of subunit: a single 'heavy' subunit of molecular weight (MW) 28,000 noncovalently attached to a $58,000-\mathrm{MW}$ aggregate of 'light' subunits (Fig. 1).

The demonstration that choleragenoid, a protein immunologically related to cholera toxin and able to bind to intestinal epithelium without having toxic activity ${ }^{4}$, contains the same 'light' subunits as the toxin but lacks the 'heavy' subunit strongly suggested that the 'light' subunits are responsible for cell binding (B subunits) and the 'heavy' subunit for the direct toxic activity (A subunit $)^{11-14}$. Experiments with toxin subunit fractions, prepared by gel filtration in acidic buffer and dialysed to allow renaturation and reassociation of subunits, confirmed that $B$ subunit bound strongly both to the cell and to the isolated cell receptors, but was nontoxic. Purified A subunit neither bound to nor was toxic for intact cells. However, A reassociated with B had both binding and toxic activity in various whole-cell systems ${ }^{11-13,15,16}$.
The requirement for membrane binding by the $B$ subunits can be circumvented by using disrupted cells; in these conditions purified $A$ subunit and also its $A_{1}$ fragment (see Fig. 1) can activate adenylate cyclase ${ }^{17-19}$. Furthermore, the characteristic lag period of 10-60 min observed in intact cells before any effect of cholera toxin on adenylate cyclase is seen ${ }^{6-10}$, essentially disappears in broken cells. Reduction of the disulphide bond between the $A_{1}$ and $A_{2}$ regions, but not the physical separation of the two fragments, seems to be necessary for the activity of $A$ on adenylate cyclase $\mathrm{e}^{20}$.

\section{The cholera toxin receptor}

The first event in the action of cholera toxin on cells is the rapid, tight binding to receptors on the cell surface. Studies with

${ }^{125}$ I-labelled toxin have shown that binding occurs almost instantaneously, is saturable and initially reversible ${ }^{15,21}$. The number of binding sites per cell varies widely with the cell type but affinity of binding varies very little $\left(K_{\mathrm{A}} \sim 1 \times 10^{9} \mathrm{~mol}^{-1}\right)$ indicating that the receptor is the same for various cell types ${ }^{21-2,3}$.

It is now known that the membrane receptor for cholera toxin is a specific ganglioside (Fig. 2). Van Heyningen et al. ${ }^{24}$ observed that a crude ganglioside mixture inactivated cholera toxin; J.H. et $a l^{25}$, Cuatrecasas ${ }^{21}$ and King and van Heyningen ${ }^{26}$ showed that this inactivation resulted from specific binding between the toxin and a single ganglioside, $G_{M 1} . G_{M 1}$ neutralized cholera toxin in about equimolar proportions and gave a specific precipitation band with cholera toxin in gel-diffusion tests ${ }^{25}$.

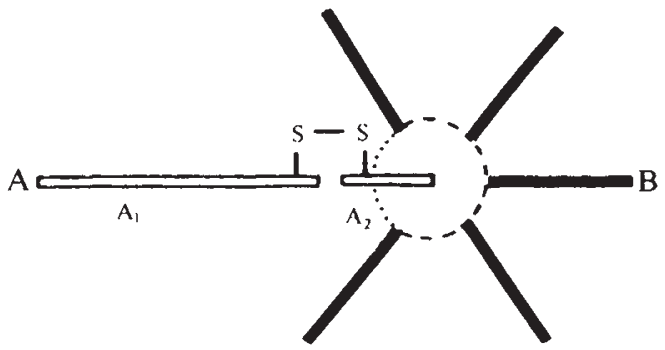

Fig. 1 Model of cholera toxin subunit structure. The toxin has one 28,000-MW A subunit and five 11.600-MW B subunits $^{11-16,29,62,102-107}$. The $B$ subunits, which contain 103 residues 9 and 86 (refs 105, 106), are aggregated in a ring by tight, noncovalent bonds. The $A$ subunit is linked to and partially inserted in the B ring through weaker noncovalent interactions ${ }^{45}$. A subunit, although synthesized as a single polypeptide chain (one gene $)^{108}$, is usually 'nicked' between its two cysteine residues by bacterial protease(s) and thus splits into fragments $A_{1}$ (MW $\sim 21,000)$ and $\mathbf{A}_{2}(\mathbf{M W} \sim 7,000)$ when treated with thiol-reducing agents ${ }^{11-15,62}$. Reduction of whole toxin releases the $A_{1}$ fragment from the $A_{2}-5 B$ complex, indicating that $A$ is attached to the $B$ ring by its $\mathrm{A}_{2}$ portion ${ }^{102,109}$. Electron micrographs show the outer diameter of the $B$ ring to be $90-100 \AA$, and the size of the separated $A$ and $B$ subunits as $\sim 35 \times 55 \AA$ and $\sim 24 \times 30 \AA$ (refs 110,45 ). 
Subsequent studies in several laboratories have provided further evidence that ganglioside $G_{M 1}$ is the natural biological receptor for cholera toxin.

(1) Studies of various cell types, including small intestinal mucosal cells of different species, have demonstrated a direct relationship between the cell content of $G_{M 1}$ and the number of toxin molecules that the cells can bind ${ }^{22,27.28}$. In each cell type studied there have been about five molecules of $G_{M 1}$ per toxin binding site $e^{27}$, which supports data from in vitro fixation stu$\operatorname{dies}^{29-32}$ that each toxin $B$ subunit binds to one $G_{M 1}$ molecule.

(2) Exogenous $G_{M 1}$ ganglioside can be incorporated into the cell membrane, there to act as a functional receptor. This was first shown by Cuatrecasas ${ }^{33}$, who observed an increased cholera toxin-binding capacity and lipolytic responsiveness of fat cells which had been soaked in $G_{M 1}$. Using ${ }^{3} H$-labelled $G_{M 1}, J . H$. et al. ${ }^{22}$ demonstrated the incorporation of $G_{M 1}$ into epithelial membrane of small intestine from humans and other species and showed that the increase in $G_{M 1}$ was associated with a corresponding increase in the capacity of the intestine to bind cholera toxin. In vivo tests in rabbits showed parallel increases of $G_{M_{1}}$ and susceptibility of the gut to the diarrhoeogenic action of the toxin ${ }^{22}$. Incorporation of $G_{M 1}$ into transformed cells deficient in this ganglioside has restored cell responsiveness to cholera toxin ${ }^{34,35}$.

(3) Pretreatment of cell membranes with cholera toxin has been found to block specifically the membrane $G_{M 1}$ from reacting with galactose oxidase ${ }^{36}$.

(4) Incubation of certain tissues with $V$. cholerae sialidase increases the number of toxin-binding sites in proportion to the additional $G_{M 1}$ produced by the enzyme from more complex gangliosides in the membrane: cellular sensitivity to the toxin is simultaneously enhanced ${ }^{27,13-115}$. However, $V$. cholerae sialidase has failed to create new receptors for cholera toxin in intestinal epithelium ${ }^{22}$ even though after extraction, the intestinal gangliosides are normally hydrolysed by this enzyme ${ }^{22}$. Thus intestinal epithelium seems to possess a means of preserving its structural integrity from enzymatic attack.

(5) Chemical modifications of cholera toxin by various reagents have consistently and proportionally affected binding to cells and to plastic-adsorbed $\mathrm{G}_{\mathrm{M} 1}$ ganglioside ${ }^{37}$.

\section{Membrane penetration and activation of adenylate cyclase}

As already indicated, the lag between cell binding of cholera toxin and activation of adenylate cyclase mainly reflects the time taken for the toxin A subunit to penetrate the cell membrane. In comparison, the generation of $\mathrm{A}_{1}$ and the subsequent effect on adenylate cyclase are rapid events that occur in $<1 \mathrm{~min}$ (ref. 17). The cell penetration process is poorly understood; the time it takes is markedly influenced by the incubation temperature and the composition of the cell membrane (J.H. et al., unpublished results). Lateral diffusion and capping of cholera toxin in the membrane have been demonstrated ${ }^{15,38-40}$ and have been proposed to be critical for action of the toxin ${ }^{38.41}$. Lateral diffusion seems to have a much greater influence on the lag time in $\mathrm{G}_{\mathrm{M} 1}$-poor cells than in those with more receptors. Thus, cell incorporation of exogenous $G_{M 1}$ significantly shortened the lag period in C6 cells which bind 7,000 toxin molecules per cell ${ }^{42}$, while no such effect was seen for mouse thymocytes (J.H. et al., unpublished results) which bind 150,000 toxin molecules per cell and exhibit a much shorter lag period ${ }^{37}$.

Moss et al. ${ }^{43}$ and Tosteson and Tosteson ${ }^{44}$ have shown that both cholera toxin and its $B$ region can create pores in synthetic lipid bilayers containing $\mathrm{G}_{\mathrm{M} 1}$; however the observed capping of cholera toxin in viable cells suggests that the initial $G_{M 1}-$ toxin complex makes contact with an integral membrane protein. As discussed in detail elsewhere ${ }^{45}$, the association of toxin with the membrane $G_{M 1}$ receptors might induce a conformational change in the B subunits, resulting in exposure of otherwise hidden hydrophobic B-subunit regions which then fuse with hydro- phobic protein or lipid components of the plasma membrane. This could result in entry of the A subunit into the cell by one of at least three possible mechanisms. First, it is possible that the B subunits form a hydrophilic channel through the membrane, allowing $A$ to pass; second, a channel for A subunit, may be built by the $B$ subunits and an integral membrane protein; the third possibility is that a hydrophobic interaction between the $\mathrm{A}$ subunit and an integral membrane component may transpose $\mathrm{A}$ to the inner face of the membrane where intracellular glutathione would reduce the $A_{1}-A_{2}$ disulphide linkage, thereby releasing $A_{1}$. Membrane-bound cholera toxin is partly endocytosed ${ }^{27.46}$. Recent studies have suggested that for diphtheria toxin (the action of which resembles that of cholera toxin although the metabolic and clinical effects are very different ${ }^{47}$ ), adsorptive endocytosis is required for membrane penetration and cytotoxicity at physiological $p \mathrm{H}$; lysosomotropic agents protect the cells, probably by neutralizing the acid $p \mathrm{H}$ in lysosomes, thus preventing the acid-dependent conformational change of endocytosed toxin in secondary lysosomes that is necessary for the translocation of the diphtheria toxin A fragment ${ }^{48,49}$. Lysosomotropic agents, such as ammonium chloride and chloroquine, should also be tested for their effect on the activity of cholera toxin.

The intracellular biochemical events that lead to activation of adenylate cyclase are known. Gill ${ }^{\text {so }}$ showed that, in broken cell preparations, activation depends on NAD, undefined cellular cytosol factors and ATP, in addition to the $A_{1}$ fragment and cell membrane. Moss et al. ${ }^{\text {si }}$ showed that cholera toxin, like diphtheria toxin, has ADP-ribosyltransferase activity, that is, it catalyses the reaction:

NAD + acceptor protein $\rightarrow$ ADP-ribose-acceptor protein

$$
+ \text { nicotinamide }+\mathrm{H}^{+}
$$

The protein that is ADP-ribosylated by cholera toxin has recently been identified as the guanyl nucleotide-binding component of the membrane-bound adenylate cyclase $e^{52,53}$. Cassel and Selinger ${ }^{54}$ have shown that adenylate cyclase is active while GTP is bound to the GTP-binding component but reverts to an inactive state as GTP is hydrolysed to GDP by GTPase; cholera toxin blocks the GTPase action which stabilizes adenylate cyclase in an active conformation. Alternatively, cholera toxin may stimulate adenylate cyclase by enhancing an exchange reaction in which stimulatory GTP replaces inhibitory GDP at a rate higher than that of hydrolysis of GTP to GDP

\section{B subunit cholera vaccine}

Can recent knowledge about cholera toxin be used to improve prevention or treatment of disease? Although the development of the highly successful water and electrolyte substitution therapy was essentially an empirical process, three rather more specific approaches have given promising results in animals and are now being used in clinical trials.

The first of these is the development of an oral cholera vaccine based on enterotoxin $\mathbf{B}$ subunit. In contrast to clinical cholera disease, which gives rise to long-lasting immunity ${ }^{56}$, the wholecell cholera vaccines give only partial immunity for $<6$ months ${ }^{57}$. Animal studies have shown that antitoxic and antibacterial cholera immunity cooperate synergistically in the gut giving a multiplicative protective effect by interfering with separate pathogenic events-toxin binding and bacterial adhesion and colonization ${ }^{58-60}$. The whole-cell vaccines probably fail both because they lack any toxin-derived antigen and because the injection route may be relatively inefficient in stimulating local immunity in the gut mucosa ${ }^{61}$

Purified cholera B subunit, which spontaneously reassociates to the pentamer ring ${ }^{60}$, is a logical 'toxoid' immunogen against cholera, especially for oral immunization. It is immunologically unrelated to $A$ subunit ${ }^{13,29,62}$ and is a much stronger immunogen ${ }^{63}$. Furthermore, isolated antibodies to B subunit have considerably higher cholera toxin-neutralizing activity than antibodies to the $A$ subunit ${ }^{63.64}$. The separation of $B$ 


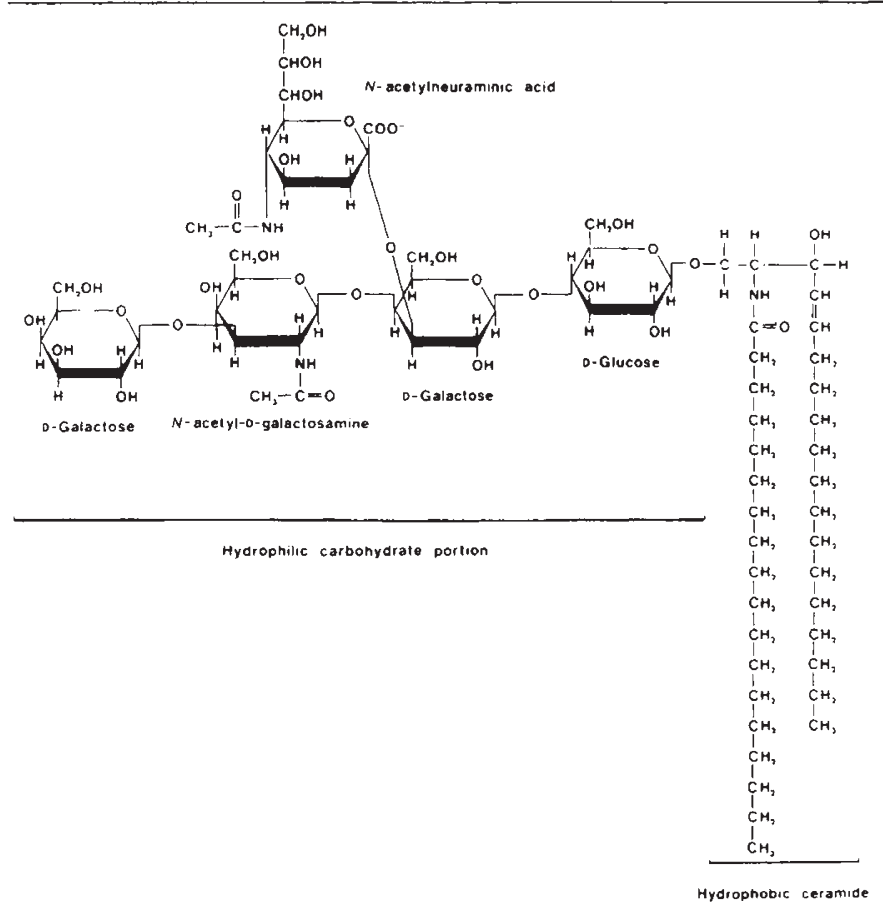

Fig. 2 Structure of the cholera toxin receptor, $G_{M 1}$ ganglioside. The oligosaccharide moiety of $G_{M 1}$ carries the binding determinants for cholera toxin, and studies have shown that both the terminal galactose and the sialic acid residues, positioned as in $G_{M 1}$, are required for receptor activity ${ }^{25,111}$. the removal or masking of any of these residues effectively inhibits the cholera toxin binding activity ${ }^{25}$. Decarboxylation of the sialic acid residue destroys the receptor activity of $\mathrm{G}_{\mathrm{M} 1}$ (ref. 30 and $\mathrm{L}$. Svennerholm et al., in preparation), while oxidation with sodium periodate or exchange of the $\mathrm{N}$-acetyl group by $\mathrm{N}$-glycolyl does not affect activity (ref. 34 and L. Svennerholm et al., in preparation). The lipid moiety of $G_{M 1}$ is also important. A sufficiently long hydrocarbon chain is needed for stable fixation of cholera toxin $^{31,122}$. Lyso- $G_{M 1}$, in which the fatty acid has been replaced by an acetyl group, has been shown both to have intact toxin-binding activity ${ }^{31}$ and to be even better than $G_{M 1}$ in promoting subsequent toxin-membrane interactions necessary for activation of adenylate cyclase $^{34}$

subunit from A excludes any risk of reversion to toxicity but does not lead to significant loss of protective antigen determinants ${ }^{60}$. B subunit is particularly well suited to oral immunization because it retains the ability to bind to the intestinal epithelium, which has been shown to be important for stimulating mucosal immunity in animals, including local immunological memory ${ }^{61}$. Finally, as will be further discussed, B subunit given orally may also provide nonimmunological protection by blocking receptors before stimulating local immunoglobulin A ( $\mathrm{IgA})$ antitoxin formation. Purified B subunit is a strong protective antigen against experimental cholera in rabbits when given either alone or in combination with somatic antigens ${ }^{60}$. It was recently tested ${ }^{65}$ for its ability to stimulate mucosal immunity in humans; a single oral administration stimulated a marked local secretory IgA antibody response in $80 \%$ of the recipients. The response was comparable to that evoked in cholera patients by the natural disease ${ }^{66}$. In further studies, two oral immunizations with a mixture of $B$ subunit and whole-cell vaccine have produced secretory $\operatorname{IgA}$ antibody responses in intestine both to the toxin and the bacterial cell-wall lipopolysaccharide antigens in almost all people vaccinated ${ }^{67}$. These results are promising but protective efficacy of an oral combined $\mathrm{B}$ subunit-whole cell vaccine in people living in areas in which cholera is endemic will require evaluation by field trials. The production of sufficient amounts of $B$ subunit should not pose any problem, due to the recent development of affinity chromatography purification using a $G_{M 1}$ column $^{68}$.

Genetic methods may also supply $V$. cholerae strains which selectively lack the gene for the 'toxic' A subunit. By retaining the ability to colonize the intestine and produce immunogenic $B$ subunit, such strains could be useful as live oral cholera vaccines. It must be borne in mind, however, that any living vaccine of this sort will require thorough testing for stability, and lack of side effects before it can be used in humans. In that respect it is disappointing that the first such $V$. cholerae strain (Texas star) ${ }^{69}$, produced diarrhoea (although usually very mild) in about $20 \%$ of recipient American volunteers in spite of producing no detectable holotoxin when grown in vitro ${ }^{70}$.

\section{Receptor-specific interference with toxin binding}

The second rational approach to cholera prophylaxis is based on the identification of $G_{M 1}$ as the toxin receptor. In theory, the oral administration of large amounts of $\mathrm{G}_{\mathrm{M} 1}$ or a structural analogue could be used to prevent binding of the toxin to cell receptors. Alternatively, cell receptors could be blocked by the nontoxic B subunit.

Development of cholera was prevented by giving $G_{M 1}$ to rabbits $^{30}$, but for prophylactic medical use, enough $G_{M 1}$ would have to be given to ensure an excess in relation to the amount of toxin produced by the cholera vibrios in the gut. Most clinical isolates of $V$. cholerae produce considerably less than $1 \mu \mathrm{g} \mathrm{ml}^{-1}$ of cholera toxin when grown in vitro, and toxin concentrations in diarrhoeal fluid of patients have not been found to exceed $0.2 \mu \mathrm{g}$ $\mathrm{ml}^{-1}$ (refs 71,116$)$. Assuming a daily production of $\sim 10 \mathrm{nmol}$ of cholera toxin in $\sim 51$ of small intestinal juice, neutralization of the toxin should be accomplished by a similar amount of $G_{M 1}$. To avoid the incorporation of oral $G_{M 1}$ into intestinal cells, which would increase their susceptibility to cholera ${ }^{22}$, the toxin could be adsorbed onto medical charcoal ${ }^{71}$, or covalently coupled to cellulose powder, for example (L. Svennerholm et al., in preparation).

As $G_{M 1}$ cannot deactivate toxin that has already bound to the intestine, it would be expected to have a preventive rather than a curative effect. However, in a recent clinical trial the amount of $\mathrm{G}_{\mathrm{M} 1}$-charcoal that completely bound the free, luminal $V$. cholerae enterotoxin also reduced purging in the early stage of disease $\mathrm{e}^{71}$. The most likely explanation for this observation is that, because of the constant and rapid regeneration of gastrointestinal cells, there are always new cells available to bind cholera toxin or to be protected by an agent that binds the toxin. This is probably the first instance in which a specific receptor has been used to interfere with an infectious disease. However, it should be emphasized that the observed effect of $G_{M 1}$-charcoal was too transient and incomplete to be practically useful; rather, $\mathrm{G}_{\mathrm{M} 1}$ given orally would possibly be useful for prophylaxis in high-risk groups such as family contacts of cholera patients.

As the B subunit of cholera toxin binds tightly to $\mathrm{G}_{\mathrm{M} 1}$ receptors but has no toxic activity, it might be possible to block the intestinal receptors by occupying them with purified $B$ subunit protomer. It has been shown that pretreatment of the gut of rabbits with $0.5 \mu \mathrm{g}$ of $\mathrm{B}$ subunit per cm completely protected the animals from experimental cholera after challenge with high doses of active cholera toxin ${ }^{22.72 .73}$. A human trial is conceivable now that it is technically possible to prepare purified $B$ subunit in sufficient quantities ${ }^{68}$; as little as $\sim 100 \mu \mathrm{g}$ of B subunit could theoretically block all available receptors, based on the determination of amounts of $G_{M 1}$ in human intestinal epithelium ${ }^{22}$. B subunit is both safe and specific, and might prevent manifestation of disease while inducing local antitoxic immunity and allowing the infection to elicit an antibacterial immune response. In contrast to prophylactic $\mathrm{G}_{\mathrm{M} 1}$, B subunit would also block toxin which is secreted in close proximity to the microvilli.

\section{Antisecretory drugs}

The third approach, intended for therapy rather than prophylaxis, aims at specifically reversing the toxic action after the cholera toxin has become bound to the intestinal cells. During the past decade oral hydration therapy by means of appropriate glucose-electrolyte solutions has greatly simplified the treatment of dehydrating diarrhoea, making effective therapy feasible in situations where intravenous treatment facilities are limited or unavailable ${ }^{74-76}$. This treatment takes advantage of the presence of an uptake mechanism for sodium in conjunction 
with certain organic solutes, including glucose, which is not regulated by cyclic nucleotides and thus is unaffected in cholera and other forms of enterotoxic diarrhoea ${ }^{77}$. In patients with mild or moderate dehydration the success rate with oral therapy is very high, usually more than $90 \%$. However, in severely affected patients purging often occurs at such a high rate that balance cannot be maintained by oral fluid only, and intravenous replacement of fluid is essential for survival. Drugs that could reduce, the rate of fluid loss in the severe dehydrating diarrhoeal diseases would obviate the need for much intravenous therapy and thus could play an important part in the management of severe diarrhoea. Such antisecretory drugs would need a high therapeutic index so that they could be used without extensive medical supervision, and they would have to be compatible with oral fluid therapy.

Based on present understanding of the biochemical events initiated by cholera toxin, possibilities for specific intervention include: (1) prevention of entry of A subunit (although not clinically useful as this event occurs before the onset of symptoms); (2) use of purines and their analogues to alter the NADase action of cholera toxin; (3) use of alternative acceptors, such as arginine or imidazoles, for the ADP-ribose generated by the toxin; (4) reversal of the ADP-ribose-adenylate cyclase association; and (5) removal of ADP-ribose by a specific ADPribosidase. While some of these approaches have reversed the action of cholera toxin in vitro in broken cell systems, kinetic and other considerations make the likelihood of success of inhibiting this stage of the secretory process in vivo extremely remote ${ }^{78}$.

There seem to be considerably greater opportunities for inhibiting the action of cholera toxin subsequent to the ADP ribosylation step by interfering with cyclic AMP formation or metabolism, or by modulating electrolyte-translocating mechanisms of the intestinal membrane. Several drugs have been found to inhibit secretion induced by cholera toxin in experimental animals, for example, chlorpromazine ${ }^{79}$ and certain related compounds ${ }^{80}$, nicotinic $\operatorname{acid}^{81}$, aspirin ${ }^{82}$, indomethacin $^{83}$, ethacrynic acid ${ }^{84}$, propranolol ${ }^{85}$, lidocaine ${ }^{86}$ and berberine 117 (for review see ref. 118). Chlorpromazine is the best studied of these drugs. In mice, treatment intramuscularly or enterally with 1-4 mg of chlorpromazine per $\mathrm{kg}$ body weight completely inhibited the intestinal secretion caused by cholera toxin, Escherichia coli $\mathrm{LT}$, prostaglandin $\mathrm{E}_{1}$ or dibutyryl cyclic $\mathrm{AMP}^{79}$. In similar doses, chlorpromazine reversed fluid loss in piglets with enterotoxinogenic $E$. coli diarrhoea ${ }^{87}$. In adult patients with severe cholera, treatment with chlorpromazine either perorally or intramuscularly, in a single dose of 1 or $4 \mathrm{mg}$ per $\mathrm{kg}$, rapidly and drastically reduced the purging volumes by $\sim 65 \%$ (ref. 88 ). The patients became mildly sedated, were more comfortable, and had no nausea or vomiting. A follow-up clinical trial has shown that treatment of children with $1 \mathrm{mg}$ per $\mathrm{kg}$ chlorpromazine increased the success rate of oral hydration therapy in patients with severe cholera ${ }^{89}$.

The mechanism of antisecretory action of chlorpromazine is not fully known; however, it does seem to be confined to the intestinal epithelium ${ }^{79,90,91}$. Chlorpromazine was selected for testing because of its ability to inhibit hormonal stimulation of cyclic AMP formation in various tissues ${ }^{92,93}$; both the cholera toxin-and fluoride-stimulated adenylate cyclase activities of the intestinal mucosal membrane of chlorpromazine-treated mice are suppressed ${ }^{79}$. However, the activity of the protein kinase of mucosal membranes is also reduced, suggesting multiple effects of chlorpromazine ${ }^{79}$. In the brain, chlorpromazine and other phenothiazines are known to inactivate calmodulin and to interfere with transfer of calcium across the nerve-cell membrane ${ }^{94}$; if these effects occur in the intestine, they could lead to inhibition of secretion ${ }^{91119}$. The action of chlorpromazine on calmodulin could possibly be linked to an inhibitory effect on adenylate cyclase.

\section{Perspective}

It has been estimated that each year about 1,000 million episodes of acute diarrhoea occur in children under 5 years of age in Asia, Africa and Latin America, resulting in 5 million deaths. In many developing countries one-third to one-half of infant mortality can be attributed to diarrhoeal diseases. Even in the older age groups diarrhoeal episodes are frequent causes of severe illness and death ${ }^{95,96}$.

Cholera is not the most prevalent of the diarrhoeal diseases, but it causes the most severe fluid loss and thus is responsible for a large proportion of life-threatening illness and death during the cholera season in endemic areas. Furthermore, research during the past decade has also made it clear that cholera is a prototype of diarrhoeal diseases caused by other enterotoxinproducing bacteria, especially $E$. coli ${ }^{97}$. Taken together, the enterotoxic enteropathies probably account for at least one-half of dehydrating diarrhoeal illnesses. Knowledge of the structure and function of cholera toxin has been the main stimulus and provided guidelines for recent research in elucidating the aetiology and pathogenesis of these related diarrhoeas. Diagnostic assays for $E$. coli $\mathrm{LT}$ based on toxin-induced cyclic AMP manifestations in animals or cell lines ${ }^{98.99}$, or more recently, on immunological $^{100}$ or receptor-immunological methods ${ }^{101}$ are based on similar methods for cholera toxin.

Although clean water supplies and safe disposal of human sewage would effect a dramatic reduction in cholera and other diarrhoeal disease, these two goals cannot be achieved in many areas for decades. If effective vaccines could be developed, they would no doubt be important components of national control programmes against diarrhoeal disease. The same holds true for drugs that could prevent or reduce fluid loss in enteric infections and thus alleviate the need for intravenous treatment.

Here I have described some theoretically possible approaches to counteract cholera toxin by immunological or pharmacological means. While each of these methods have been effective against cholera in animal studies, and, to the limited extent to which they have been tested, have also given promising results in man, much more research is needed to define their place, if any, in future prophylaxis and treatment of cholera. They should be regarded merely as starting points for further development. For example, in relation to vaccine development there is a need for better understanding of factors regulating the magnitude and duration of intestinal antitoxic as well as antibacterial immunity. With regard to receptor-prophylactic agents, basic research should be directed to identify specific binding or blocking agents for cholera vibrios which might cooperate synergistically with those for toxin. In the case of antisecretory agents, the aim should be to find drugs which effectively depress secretion but lack the sedative action of chlorpromazine. However, it is gratifying that cholera toxin research has now reached the stage where rational counteractive methods can be both formulated on the basic molecular knowledge, and, most importantly, be evaluated in controlled clinical and field trials.

I thank the many colleagues who contributed much to the cited work from this laboratory. I particularly thank Professor Lars Svennerholm and his group for close collaboration on all aspects of $G_{M 1}$ ganglioside as receptor for cholera toxin; Drs Ann-Mari Svennerholm and Ivar Lonnroth for aspects relating to immunity and vaccine development, and antidiarrhoeal action of phenothiazines, respectively; Dr William B. Greenough and his staff at the International Centre for Diarrhoeal Disease Research, Dacca for the clinical trials; Institut Merieux, Lyon and SBL, Stockholm, for technical collaboration and for preparing $G_{M 1}$-charcoal and $B$ subunit for the clinical tests; and Dr Charles Wadsworth for his criticisms of the manuscript and helpful comments.

\footnotetext{
1. Ouchterlony, O. \& Holmgren, J. (eds) Cholera and Related Diarrhoeas: 43rd Nobel Symp., Stockholm 1978 (Karger, Basel, 1980)

. De, S. N. Nature 183, 1533-1534 (1959)

3. Dutta, N. K., Panse, M. V. \& Kulkarni, D. R. J. Bact. 78, 594-595 (1959).

4. Finkelstein, R. A. \& LoSpalluto, J. J. J. exp. Med. 130, 185-202 (1969).

5. Richardson, S. H., Evans, D. G. \& Feeley, J. C. Infect. Immunity 1, 546-553 (1970).

6. Field, M., Fromm, D., Waliace, C. K. \& Greenough, W. B. J. clin. Invest. 48, 24a (1969).

7. Schafer, D. E., Lust, W. D., Sircar, B. \& Goldberg, N. D. Proc. natn. Acad. Sci. U.S. A. 67, $851-856(1970)$.

8. Sharp, G. W. G. \& Hyлie, S. Nature 229, 266-269 (1971)

9. Field. M., Fromm, D., Al-Awqati, Q \& Greenough, W. B. J. clin. Invest. 51, 795-804 (1972)
} 
10. Greenough, W. B., Pierce, N. F. \& Vaughan, M. J. infect. Dis. 121, S111-S114 (1970).

11. Lönnroth, 1. \& Holmgren, J. J. gen. Microbiol. 76, 417-427 (1973).

12. Cuatrecasas, P., Parikh, I. \& Hollenberg, M. D. Biochemistry 12, 4253-4264 (1973).

13. Holmgren, J. Proc. 9th Joint US-Japan Cholera Conf., Grand Canyon 1973, 196-213 (Dept of State Publ. 8762, Washington, 1973).

14. Heyningen, S. van. Science 183, 656-657 (1974)

15. Holmgren, J., Lindholm, L. \& Lönnroth, I. J. exp. Med. 139, 801-819 (1974).

16. Finkelstein, R. A., Boesman, M., Neoh, S. H., LaRue, N. K. \& Delaney, R. J. Immun. 113. $175-180(1974)$

17. Gill, D. M. \& King, C. A. J. biol. Chem. 250, 424-432 (1975)

18. Heyningen, S. van \& King, C. A. Biochem. J. 146, 269-271 (1975)

19. Flores, J. \& Sharp, S. W. G. J. clin. Invest. 56, 1345 1349 (1975).

20. Mekelanos, J. J., Collier, R. J. \& Romig, W. R. J. biol. Chem. 254, 5855-5861 (1979).

21. Cuatrecasas, P. Biochemistry 12, 3547-3558 (1973).

22. Holmgren, J., Lönnroth, 1., Månsson, J. E. \& Svennerholm, L. Proc. natn. Acad. Sci. U.S.A. 72, 2520-2524 (1975).

23. Fishman, P. H. \& Atikkan, E. E. J. biol. Chem. 254, 4342-4344 (1979).

24. Heyningen, W. E. van, Carpenter, C. C. J., Pierce, N. F. \& Greenough, W. B. J. infect. Dis. 124, 415-418 (1971).

25. Hoimgren, J., Lönnroth, I. \& Svennerholm, L. Infect. Immunity 8, 208-214 (1973)

26. King, C. A. \& Heyningen, W. E. van. J. infect. Dis. 127, 639-647 (1973).

27. Hansson, H.-A., Holmgren, J. \& Svennerholm, L. Proc. natn. Acad. Sci. U.S.A. 74, 3782-3786 (1977).

28. Fishman, P. H. \& Atikkan, E. E. J. biol. Chem. 254, 4342-4344 (1979)

29. Holmgren, J. \& Lönnroth, I. J. gen. Microbiol. 86, 49-65 (1975)

30. Sattler, J., Schwarzmann, G., Staerk, J., Ziegler, W. \& Wiegandt, H. Hoppe-Seyler's Z. physiol. Chem. 358, 159-163 (1977).

31. Holmgren, J., Månsson, J.-E. \& Svennerholm, L. Med. Biol. 52, 229-233 (1974)

32. Fishman, P. H., Moss, J. \& Osborne, J. C. Biochemistry 17, 711-716 (1978)

33. Cuatrecasas. P. Biochemistry 12, 3558-3566 (1973).

34. Fishman, P. H., Pacuszka, T., Holm, B. \& Moss, J. J. biol. Chem. 255, 7657-7664 (1980).

35. Moss, J., Fishman, P. H., Manganiello, V. O., Vaughan, M. \& Brady, R. O. Proc. natn. Acad Sci US A. 73, 1034-1037 (1976)

36. Mullin, B. R. et al. Proc, natn. Acad. Sci. U.S.A. 73, 1679-1683 (1976)

37. Holmgren, J. \& Lönroth, I. J. infect. Dis. 133, 564-574 (1976)

38. Craig, S. W. \& Cuatrecasas, P. Proc. nain. Acad. Sci. U.S.A. 72, 3844-3848 (1975)

39. Revesz, T. \& Greaves, M. Nature 257, 103-106 (1975).

40. Sedlacek, H. H., Staerk, J., Seiler, F. R., Ziegler, W. \& Wiegand, H. FEBS Lett. 61, $272-276(1976)$

41. Bennet, V., O'Keefe, E. \& Cuatrecasas, P. Proc notn Acad. Sci. U S.A 72, 33-37 (1975)

42. Fishman P. H in Secretory Diarthea (eds Field M. Fordtran, J. S. \& Schultz S. G. 85-106 (American Physiological Society, Maryland, 1980).

43. Moss, J., Richards, R. L., Alving, C. R. \& Fishman, P. H. J. biol. Chem. 252, 797-798 (1977).

44. Tosteson, M. T. \& Tosteson, D. C. Nature 275, 142-144 (1978).

45. Holmgren, J. \& Löntroth, I. in Cholera and Related Diarrhoeas: 43rd Nobel Symp., Stockholm 1978, 88-103 (Karger, Basel, 1980).

46. Manuelidis, L. \& Manuelidis, E. E. J. Neurocytol. 5, 575-589 (1976)

47. Pappenheimer, A. M. Jr A. Rev. Biochem. 46, 69-94 (1977).

48. Sandvig, K. \& Olsnes, S. J. Cell Biol. 87, 828-832 (1980).

49. Draper, R. K. \& Simon, M. I. J. Cell Biol. 87, 849-854 (1980).

50. Gill, D. M. J. infect. Dis. 133, S55-S63 (1976).

51. Moss, J., Manganiello, V. C. \& Vaughan, M. Proc. natn. Acad. Sci. U.S. A. 73, 4424-4427 (1976)

52. Cassel, D. \& Pfeuffer, T. Proc. natn. Acad. Sci. U.S.A. 75, 2669-2673 (1978).

53. Gill, D. M. \& Mehren, R. Proc. natn. Acad. Sci. U.S.A. 75, 3050-3054 (1978)

54. Cassel, D. \& Selinger, Z. Proc. natn. Acad. Sci. U.S.A. 74, 3307-3311 (1977).

55. Lad, P. M., Nielsen, T. B., Preston, N. S. \& Rodbell, M. J. biol. Chem. 255, 988-995 (1980)

56. Cash, R. A. et al. J. infect. Dis. 130, 325-333 (1974).

57. Feeley, J. C. \& Gangarosa, E. J. in Cholera and Related Diarrhoeas: $43 \mathrm{rd}$ Nohel Symp. Stockholm 1978, 204-210 (Karger, Basel, 1980).

58. Svennerholm. A.-M. \& Holmgren, J. Infect. Immunity 13, 735-740 (1976).

59. Peterson, J. W. Infect. Immunity 26, 528-533 (1979).

60. Holmgren, J. et al. Nature 269, 602-604 (1977).

61. Pierce, N. F. J. exp. Med. 148, 195-206 (1978)

62. Ohtomo, N., Muraoka, T. \& Tashiro, A. Proc. 1Oth Joint US-Japan Cholera Conf., Kyoto 1974, 115-118 (Tokyo, 1974)

63. Svennerholm, A.-M. in Cholera and Related Diarrhoeas: 43rd Nobel Symp., Stockholm 1978, 171-184 (Karger, Basel, 1980).

64. Peterson, J. W., Heitmancik, K. E., Markel, D. E., Craig, J. P. \& Kurosky, A. Infect Immunity 24, 774-779 (1979).

65. Svennerholm, A.-M., Sack, D. A.. Bardhan, P. K., Jertborn, M. \& Holmgren, J. in Proc. I6th US-Japan Cholera Conf. Gifu, 1980 (Osaka University Press, in the press).

66. Sack, D. A. Islam, A. Holmgren, J. \& Svennerholm, A. - M. in Proc. 15th Joint US-Japan Cholera Conf. Bethesda, 1979, 423-439 (NIH Publ. 80-2003, 1980).
67. Svennerholm, A.-M., Jertborn, M., Gothefors, L., Sack, D. A. \& Holmgren, J. (in preparation).

68. Tayot, J.-L., Holmgren, J., Svennerholm, L., Lindblad, M. \& Tardy, J. Eur. J. Biochem $113,249-258(1981)$

69. Honda, T. \& Finkelstein, R. A. Proc. nain. Acad. Sci. U.S.A. 76, 2052-2056 (1979)

70. Levine, M. in Nobel Conf. 3 (eds Holme, T., Holmgren, J., Merson, M. \& Möllby, R.) (Elsevier, Amsterdam, in the press).

71. Stoll, B. J. et al. Lancet ii, $888-891$ (1980)

72. Pierce, N. F. J. exp. Med. 137, 1009-1023 (1973)

73. Holmgren, J. Infect. Immunity 8, 851-859 (1973).

74. Hirschhorn, N. J. et al. New Engl. J. med. 279, 176-184 (1968)

75. Nalin. D. R., Cash, R. A., Islam, R., Molla. M. \& Phillips, R. A. Lancet ii, 370-372 (1968).

76. Pierce, N. F. et al. Ann. intern. Med. 70, i173-1183 (1969).

77. Schultz, S. G. \& Curran, P. F. Curr. Topics Membrane Transport 5, 225-281 (1974).

78. Greenough, W. B. III \& Hendrix, T. R. in Cholera and Related Diarrhoeas: 43rd Nobel Symp., Stockholm 1978, 234-244 (Karger, Basel, 1980).

79. Holmgren, J Lange S \& Lönnroth, I Gastroenterology 75, 1103-1108 (1978)

80. Lönnroth, I., Lange, S. \& Holmgren, J. in Phenothiazines and Structurally Related Drugs: Basic and Clinical Studies (eds Usdin, E., Eckert, H. \& Forrest, S. J. J.) 303-306 (Elsevier, New York, 1980)

81. Turjman, N., Gotterer, G. S. \& Hendrix, T. R. J. clin. Invest. 61, 1155-1160 (1978).

82. Finch, A. D. \& Katz, R. L. Nature 238, 273-274 (1972).

83. Jacoby, H. I., \& Marshall, C. H. Nature 235, 163-165 (1972).

84. Carpenter, C. C. J., Curlin, G. T. \& Greenough, W. B. III J. infect. Dis. 120, 332-338 (1969).

85. Taub, M., Bonorris, G., Chung, A., Coyne, M. J. \& Schoenfeld, L. J. Gastroenterology 72, $101-105$ (1977)

86. Cassuto, J., Jodal, M., Tuttle, R. \& Lundgren, O. Experientia 35, 1467-1468 (1979).

87. Lönnroth, I., Andrén, B., Lange, S., Martinsson, K. \& Holmgren, J. Infect. Immunity 24, 900-905 (1979).

88. Rabbani, G. H., Greenough, W. B. III, Hoimgren, J. \& Lönnroth, I. Lancet i, 410-412 (1979).

89. Islam, M. R., Sack, D. A., Holmgren, J., Bardhan, P. K. \& Rabbani, Lancet (submitted). 90. Lönnroth, 1. \& Munck. B. G. Acta pharmac. tox. 47. 439-446 (1979).

91. Smith, P. L. \& Field, M. Gastroenterology 78, 1545,-1553(1980)

92. Kakiuchi, S. \& Rail, T. W. Molec. Pharmac. 4, 367-378 (1968).

94. Cheung, W. Y., Lynch, T. J. \& Wallace, R. W. Adv. Cyclic Nucleotide Res. 9. 233-251 (1978)

95. Mata, L., Kronmal, R. A. \& Villegas, H. in Cholera and Related Diarrhoeas: 43rd Nobel Symp. Stockholm 1978, 1-14 (Karger, Basel, 1980)

96. Barua, D. in Nobel Conf. 3 (eds Holme, T., Holmgren, J., Merson, M. \& Móllby, R.) (Elsevier, Amsterdam, in the press).

97. Sack R B A Rev Microbiol 29, 333-353 (1975).

98. Donta, S. T. \& Smith. D. M. Infect. Immunity 9, 500-505 (1974)

99. Guerrant, R. L., Brunton, L. L., Schnaitman, T. C., Rebhun, L. I. \& Gilman, A. G. Infect. Immunity 10, 320-327 (1974).

100. Yolken, R., Greenberg, H. B., Merson, M., Sack, R. B. \& Kapikian, A. Z. J. clin. Microbiol. 6, 439-444 (1977)

101. Svennerholm, A.-M. \& Holmgren, J. Curr. Microbiol. 1, 19-27 (1978)

102. Sattler, J et al. Eur. J. Biochem. 57, 309-316 (1975).

103. Gill, D. M. Biochemistry 15, 1242-1248 (1976).

104 . Lai, C. -Y. Mendez, E. \& Chang, D. J. infect. Dis. 133, S23-S30 (1976).

105. Kurosky, A., Markel, D. E. \& Peterson, J. W. J. biol. Chem. 252, 7257-7264 (1977),

106. Lai, C.-Y. J. biol. Chem. 252, 7249-7256 (1977)

107. Sigler, P. B., Druyan, M. E., Kiefer, H. C. \& Finkelstein, R. A. Science 197, 1277-1279 (1977).

108. Gill, D. M. \& Rappaport, R. S. J. infect. Dis. 139, 674-680 (1979).

109. Tomasi, M. Battistini, A., Araco, A., Roda, L. G. \& D'Agnolo, G. Eur. J. Biochem. 93, $621-627(1979)$

110) Ohtomo, N., Muraoka, T Tashiro, A., Zinnaka, Y \& Amako, K. J. infect. Dis. 133. (Suppl.), S31-S40 (1976).

11. Fishman, P. J., Moss, J., Richards, R. L., Brady, R. O. \& Alving, C. R. Biochemistry 18, $2562-2567$ (1979).

112. Staerk, J., Ronneberger, H. J., Wiegandt, H. \& Ziegler, W. Eur. J. Biochem. 48, 103-110 (1974)

113. Haksar, A. Maudsley, D. V. \& Péron, F. G. Nature 251, 514-515 (1974).

114. Révész T Greaves, M. F Capellaro, D. \& Murray, R. K. Br. J. Haemat. 34, 623-630 (1976)

115. Holmgren, J. in Bacterial Toxins and Cell Membranes (eds Jeljaszewicz, 1. \& Wadström, T.) 333-366 (Academic, London, 1978)

16. Craig. J. P. Nature 207, 614-616 (1965).

117. Sack, R. B. in Nobel Conf. 3 (eds Holme, T., Holngren, J., Merson, M. \& Möllby, R. Elsevier, Amsterdam, in the press).

118. Powell, D. W. \& Field, M. in Secretory Diarrhoea (eds Field, M., Fordtran, J. S. \& Schultz. S. G.) 187-209 (American Physiological Society, Maryland, 1980).

119. Jlundain, A. \& Naftalin, R. J. Nature 279, 446-448 (1979).

\section{ARTICLES}

\section{High noble metal concentrations in a late Pliocene sediment}

\section{Frank T. Kyte*t, Zhiming Zhou* \& John T. Wasson* ${ }^{* \neq}$}

* Institute of Geophysics and Planetary Physics, †Department of Earth and Space Sciences, $\ddagger$ Department of Chemistry, University of California, Los Angeles, California 90024, USA

A 2.3-Myr-old layer in a sediment from the Antarctic Ocean contains Ir and Au at levels comparable with those at the Cretaceous-Tertiary boundary. A sizable fraction of the noble metals is contained in vesicular, millimetre-sized polymineralic grains that closely resemble ablation debris from chondritic meteorites, and there is little doubt that the noble metals resulted from the accretion of a large extraterrestrial object. No massive extinctions or other evidence of environmental stress seem to be associated with this accretionary event. 